ORIGINAL RESEARCH

\title{
Injury Profile of Children 0-14 Years Old in Honduras
}

\author{
Kevin D Long ${ }^{1}$, Francisco J Bonilla-Escobar ${ }^{2}$, Cristina Rodriguez ${ }^{3}$, Juan C Puyana ${ }^{4}$
}

\begin{abstract}
Aim: At the University Medical School Hospital in Honduras, a paper-based injury surveillance system (InSS) registered all injury cases in the emergency department in 2013. This is the first study to identify the injury profiles of children in Honduras, using the InSS data.

Materials and methods: A case-series study was carried out using the InSS. Children aged 0-14 years were identified in the data set, and the descriptive statistics and bivariate analyzes were completed using this data.

Results: Of 17,971 study patients, 5,873 (32.7\%) patients were $0-14$ years old with an average age of $7.3 \pm 4.1$ years. Unintentional injuries, most commonly road traffic incidents, falls, and blunt force trauma, constituted $94.2 \%$ of the total injuries. In all, $1.9 \%$ (109) self-inflicted injuries and $3.9 \%$ (230) deliberate interpersonal injuries with $35.8 \%$ due to blunt force trauma and $22.6 \%$ due to gunshot wounds. The mortality rate was $0.2 \%$, and $84 \%$ of children spent 3 or fewer days in the hospital. Firearm injuries were more severe and resulted in a longer hospital stay.

Conclusion: Childhood injuries are highly prevalent and a public concern throughout Honduras. This study profiles these injuries of over an entire year and provides insight into the types of interventions that could be effective in preventing and managing the high burden of pediatric injuries in this region.
\end{abstract}

Clinical significance: This study provides the groundwork to profiling the high burden of injuries in Honduran children. Targeted injury prevention strategies and interventions can begin to be developed and implemented using the profile.

Keywords: Child, Honduras, Public Health Surveillance, Road traffic accidents, Wounds and Injuries.

\section{Resumen}

Objetivo: En el Hospital Escuela de la Facultad de Medicina de la Universidad de Honduras, un sistema de vigilancia de lesiones en papel (InSS) registró todos los casos de lesiones en el Departamento de Emergencias en el año 2013. Utilizando los datos del InSS, este estudio es el primero en describir el perfil de las lesiones en niños en Honduras.

Materiales y métodos: Se realizó un estudio de serie de casos utilizando el InSS. Se identificaron los pacientes de 0 a 14 años en el conjunto de datos, y se realizaron estadísticas descriptivas y análisis bivariados utilizando estos datos.

Resultados: Hubo 5.873 pacientes de $0-14$ años de un total de 17.971 pacientes (32,7\%) con una edad promedio de 7,3 $\pm 4,1$ años. Las lesiones no intencionales, más comunes fueron los eventos de tránsito, las caídas y los traumatismos contundentes; en total constituyeron el $94,2 \%$ del total de lesiones. Hubo 1.9\% (109) lesiones autoinfligidas y 3.9\% (230) lesiones interpersonales deliberadas con 35.8\% debido a traumatismos contundentes y $22.6 \%$ debido a heridas por armas de fuego. La tasa de mortalidad fue del $0,2 \%$ y el $84 \%$ de los niños pasaron 3 días o menos en el hospital. Las lesiones por arma de fuego fueron más graves y resultaron en una estancia hospitalaria más prolongada.

Conclusión: Las lesiones infantiles son altamente prevalentes y una preocupación en salud pública en Honduras. Este estudio describe estas lesiones y proporciona información sobre los tipos de intervenciones que podrían ser efectivas para prevenir y manejar la alta carga de lesiones pediátricas en esta región.

Importancia clínica: El estudio proporciona la base para perfilar la alta carga de lesiones en los niños hondureños. Estrategias e intervenciones de prevención de lesiones pueden comenzar a desarrollarse e implementarse utilizando este perfil.

Palabras clave: Niños, Honduras, Vigilancia en Salud Pública, Accidentes de tránsito, heridas y traumatismos.

Panamerican Journal of Trauma, Critical Care \& Emergency Surgery (2020): 10.5005/jp-journals-10030-1297

\section{INTRODUCTION}

Globally, over 5 million people die annually due to injuries, constituting $9 \%$ of the global mortality. ${ }^{1}$ It is estimated that over 2,000 children and teenagers worldwide die daily due to preventable injuries. ${ }^{2}$ Morbidities due to injuries often include permanent disabilities and changes in lifestyles. In 2013, approximately 973 million people suffered an injury that required medical assistance. ${ }^{3}$ Burns, road traffic injuries (RTIs), drowning, fall, and homicide are 5 of the top 15 causes of death among children aged 5-14, while burns and drowning are in the top 15 causes of death among children aged 0 to $4 .{ }^{1}$ Targeted prevention strategies at reducing the burden of injuries would reduce the overall mortality and morbidity in this population., ${ }^{4,5}$

\footnotetext{
${ }^{1}$ Global Health, Division of Trauma and Surgery, University of Pittsburgh, Pennsylvania, USA

${ }^{2}$ Department of Surgery, UPMC Presbyterian Hospital, Pittsburgh, Pennsylvania, USA

${ }^{3}$ Evaluation and Management of Information, Hospital Escuela Universitario, Universidad Nacional Autonoma de Honduras, Tegucigalpa, Honduras

${ }^{4}$ Division of Trauma and Surgery, University of Pittsburgh, Pennsylvania, USA

Corresponding Author: Francisco J Bonilla-Escobar, Department of Surgery, UPMC Presbyterian Hospital, Pittsburgh, Pennsylvania, USA, Phone: +1 412647 0421, e-mail: KDL25@pitt.edu
}

() The Author(s). 2020 Open Access This article is distributed under the terms of the Creative Commons Attribution 4.0 International License (https://creativecommons. org/licenses/by-nc/4.0/), which permits unrestricted use, distribution, and non-commercial reproduction in any medium, provided you give appropriate credit to the original author(s) and the source, provide a link to the Creative Commons license, and indicate if changes were made. The Creative Commons Public Domain Dedication waiver (http://creativecommons.org/publicdomain/zero/1.0/) applies to the data made available in this article, unless otherwise stated. 
In 2013, when the data from this study was collected, Honduras had the highest rate of homicide in the world, ${ }^{6}$ and Yacoub et al. published an injury profile of Hondurans over 15 years old, which showed that violence is a significant issue in the region. The PanAmerican Health Organization (PAHO) showed that children 5-14 years of age and young adults 15-24 years of age are most affected by injuries in Honduras, ${ }^{7}$ indicating the importance of childhood injuries, fatal or nonfatal, in this region. Yet, awareness of this issue is low. ${ }^{2}$

Childhood injury prevention strategies are invaluable in lower income areas. It is known that lower socioeconomic status increases the risk of injury morbidity and mortality, ${ }^{1}$ yet no universal prevention strategies have been created for these communities. ${ }^{8}$ Statistics on injuries drive injury prevention, creating the need for injury profiles. However, a particular weakness is observed in the health system of Honduras in obtaining health statistics. ${ }^{7}$ Morbidity and mortality data primarily comes from the Ministry of Health reports and special reports, respectively, ${ }^{7}$ but is insufficient to create detailed injury profiles.

Through funding from the Centers for Disease Control and Prevention, PAHO, and United Nations Development Programme and in partnership with the University Medical School Hospital (UMSH) in Tegucigalpa, Honduras's largest referral hospital, a paper-based injury surveillance system (InSS) was implemented in $2005 .{ }^{9}$ It included all registered cases of injuries in the emergency department. The World Health Organization (WHO) defines adult mortality rates as death in individuals aged 15 years and older, and childhood mortality in children younger than 15 years. ${ }^{10}$ Given one-third of injuries in the InSS data base were in the childhood population, a detailed analysis of the specific injury burden for this age-group was warranted.

This study aims to provide insight into the burden of both intentional and unintentional injuries in Honduras through the construction of an injury profile of children aged 0-14 years from the Honduran children assisted at UMSH from the 2013 InSS database. This injury profile will be useful for promoting effective childhood injury prevention services and policies in Honduras.

\section{Materials and Methods}

This is a retrospective study that describes the InSS in UMSH from January 1, 2013, to December 31, 2013. This period provided the most accurate and clean data available from the system due to the availability of resources for data processing and institutional support to the data collection. ${ }^{11}$ The UMSH is a core hospital caring for 1.3 million people living in the metropolitan region of Tegucigalpa, the Central District of Honduras. It is also the main referral center for 64 primary care health centers and 5 hospitals. The hospital has 1,055 beds and assists around 87,000 patients per year, of which $15 \%$ present with trauma. ${ }^{11}$

Upon arrival at the UMSH emergency room (ER), an InSS document was filled by a health-care worker by interviewing the patient or a family member. Each patient admitted with an injury received a unique case number to document a comprehensive profile of their injury or injuries. The form was a wide-ranging questionnaire including descriptive questions about the location, mechanism, severity, and intentionality of the injury. It also included demographic questions and a physical assessment of each patient. A full description of the procedures and the information contained in the surveillance form is described by Rodriguez et al. ${ }^{11}$
How to cite this article: Long KD, Bonilla-Escobar FJ, Rodriguez C, et al. Injury Profile of Children 0-14 Years Old in Honduras. Panam J Trauma Crit Care Emerg Surg 2020;9(3):202-208.

Source of support: Nil

\section{Conflict of interest: None}

The WHO separates pediatric and adult mortality rates at 15 years of age, ${ }^{10}$ so this study looks at pediatric injuries in children aged 14 years and younger. In order to compare age-groups, children were split evenly into three age-groups, namely, 0-4 years (early childhood), 5-9 years (middle childhood), and 10-14 years (early adolescents). ${ }^{12}$

Injuries were classified as either unintentional, deliberately self-inflicted or a deliberate interpersonal injury. Unintentional injuries included all nondeliberate injuries including unintentional interpersonal and intrapersonal injuries. ${ }^{5,13}$ Road traffic injuries, falls, and burns are all examples of unintentional injuries if the interviewee indicated that the injury was not purposefully done by or done to the patient. Self-inflicted injuries consisted of any intrapersonal injuries such as firearm injuries, poisonings, and blunt force traumas if the interviewees indicated that the injuries were done purposefully by the patients to themselves. A deliberate interpersonal injury consisted of any injury such as a firearm injury, sexual assault, and blunt force trauma if the interviewee indicated that the injury was done purposefully by another person to the patient.

Mechanisms of injury included RTIs, sexual assault, falls, blunt force, bladed weapon, gunshot, fire, strangulation, poisoning, explosions, drowning, pyrotechnics, bites, suffocation, contact with electricity, natural disaster, injury by foreign body, contact with machinery, gas, crushing, or other. Road traffic injuries were defined as any injury sustained while inside or outside a vehicle on a road. Blunt force trauma was defined as any physical injury that is nonpenetrating caused by a forceful impact on the body, not better defined by another category. Injuries by a foreign body were defined as any injury whether it be inhaled, ingested, penetrating, and so on that remains in the body and causes injury except gunshot wounds.

Severity was measured on a scale from 1 to 4 , with 1 meaning no apparent injury, 2 meaning slight injury (superficial injuries), 3 meaning moderate injury (fractures, stitches, etc.), and 4 meaning a severe injury (requiring surgery or intensive care). Anatomical location of injury was categorized as injuries to the head, upper limb, lower limb, trunk, systemic, or other. Head injuries included injuries to the head, eyes, ears, nose, or neck. Trunk injuries were defined as injuries to the thorax, back, abdomen, buttocks, pelvis, or genitals. Upper limb injuries were defined as injuries to the arms, forearms, hands, or fingers. Lower limb injuries were defined as injuries to the thighs, knees, legs, feet, or toes. Systemic injuries were defined as intoxication or radiation. Others were all injuries that did not fit into these classifications.

The data from the InSS were exported to Stata ${ }^{\circledR}{ }^{\circledR}$ (StataCorp, TX, USA) for quality control and analysis. All quantitative variables were described using central tendency and dispersion measures, while all categorical variables were described using frequencies and percentages. Chi-square or Fisher's exact test was used to identify the independence of the categorical variables. After checking for assumptions, $t$ tests or one-way analyzes of variance (ANOVAs) were used, respectively, to compare means of two or 
Injuries in Children in Honduras

Table 1: Characteristics of injuries based on age-group and sex

\begin{tabular}{|c|c|c|c|c|c|c|c|}
\hline \multirow[b]{2}{*}{ Injuries } & \multicolumn{2}{|c|}{$0-4$ Years } & \multicolumn{2}{|c|}{ 5-9 Years } & \multicolumn{2}{|c|}{ 10-14 Years } & \multirow[b]{2}{*}{ Total N (\%) } \\
\hline & Male N (\%) & Female N (\%) & Male N (\%) & Female N (\%) & Male N (\%) & Female N (\%) & \\
\hline Total & $1109(59.7)^{*}$ & $749(40.3)^{*}$ & $1215(63.9)^{*}$ & $688(36.2)^{*}$ & $1466(69.4)^{*}$ & $646(30.6)^{*}$ & $5,873(100)$ \\
\hline \multicolumn{8}{|l|}{ Place } \\
\hline Home & $880(79.4)$ & $615(82.1)$ & $607(50.0)^{*}$ & $395(57.4)^{*}$ & $462(31.5)^{*}$ & $298(46.1)^{*}$ & $3,261(55.5)$ \\
\hline Street & $130(11.7)$ & $69(9.2)$ & $341(28.1)^{*}$ & $150(21.8)^{*}$ & $496(33.8)^{*}$ & $170(26.3)^{*}$ & $1,357(23.1)$ \\
\hline School & $25(2.3)$ & $10(1.3)$ & $158(13.0)^{*}$ & $80(11.6)^{*}$ & $253(17.3)^{*}$ & $97(15.0)^{*}$ & $623(10.6)$ \\
\hline Other & $74(6.7)$ & $55(7.3)$ & $109(9.0)^{*}$ & $63(9.2)^{*}$ & $255(17.4)^{*}$ & $81(12.5)^{*}$ & $640(10.9)$ \\
\hline \multicolumn{8}{|l|}{ Intentionality } \\
\hline Unintentional & $1,084(97.6)$ & 727 (97.2) & $1,176(96.8)$ & $664(96.5)$ & $1,339(91.3)^{*}$ & $543(84.2)^{*}$ & $5,539(94.2)$ \\
\hline Deliberate self-inflicted & $0(0)$ & $0(0)$ & $3(0.3)$ & $3(0.4)$ & $43(2.9)^{*}$ & $60(9.3)^{*}$ & 109 (1.9) \\
\hline Deliberate interpersonal & $24(2.2)$ & $21(2.8)$ & $36(3.0)$ & $21(3.1)$ & $84(5.4)^{*}$ & $42(6.5)^{*}$ & $230(3.9)$ \\
\hline \multicolumn{8}{|l|}{ Location } \\
\hline Head & $557(50.1)$ & 387 (51.7) & $492(40.5)^{*}$ & $272(39.5)^{*}$ & $446(30.4)^{*}$ & $177(27.4)^{*}$ & $2,334(39.7)$ \\
\hline Upper limb & $283(25.5)$ & $158(21.1)$ & $465(38.3)^{*}$ & $228(33.1)^{*}$ & $555(37.9)^{*}$ & $182(28.2)^{*}$ & $1,875(31.9)$ \\
\hline Lower limb & $101(9.1)$ & $82(11.0)$ & $147(12.1)^{*}$ & $97(14.1)^{*}$ & $325(22.2)^{*}$ & $159(24.6)^{*}$ & $912(15.5)$ \\
\hline Trunk & $78(7.0)$ & $58(7.7)$ & $65(5.4)^{*}$ & $65(9.5)^{*}$ & $85(5.8)^{*}$ & $58(9.0)^{*}$ & $409(7.0)$ \\
\hline Systemic & $49(4.4)$ & $43(5.7)$ & $15(1.2)^{*}$ & $16(2.3)^{*}$ & $30(2.1)^{*}$ & $58(9.0)^{*}$ & $211(3.6)$ \\
\hline Other & $41(3.7)$ & $21(2.8)$ & $31(2.6)^{*}$ & $10(1.5)^{*}$ & $25(1.7)^{*}$ & $12(1.9)^{*}$ & $140(2.4)$ \\
\hline Recreation & $880(79.4)$ & $585(78.2)$ & $922(75.9)^{*}$ & $482(70.1)^{*}$ & $924(63.0)^{*}$ & $362(56.0)^{*}$ & $4161(70.8)$ \\
\hline Traveling/walking & $118(10.6)$ & $62(8.3)$ & $158(13.0)^{*}$ & $98(14.2)^{*}$ & $240(16.4)^{*}$ & $136(21.1)^{*}$ & $813(13.8)$ \\
\hline Working & $48(4.3)$ & $42(5.6)$ & $75(6.2)^{*}$ & $52(7.6)^{*}$ & $172(11.7)^{*}$ & $77(11.9)^{*}$ & 466 (7.9) \\
\hline Studying & $2(0.2)$ & $0(0)$ & $12(1.0)^{*}$ & $10(1.5)^{*}$ & $33(2.3)^{*}$ & $12(1.9)^{*}$ & $69(1.2)$ \\
\hline Other & $7(0.6)$ & $6(0.8)$ & $7(0.6)^{*}$ & $4(0.6)^{*}$ & $17(1.2)^{*}$ & $7(1.1)^{*}$ & $49(0.8)$ \\
\hline Unknown & $54(4.9)$ & $53(7.1)$ & $41(3.4)^{*}$ & $42(6.1)^{*}$ & $80(5.5)^{*}$ & $52(8.1)^{*}$ & $315(5.4)$ \\
\hline
\end{tabular}

*Denotes $p<0.05$ using $t$-tests or 1 -way ANOVAs between sex within age groups with selected variables

more groups based on quantitative variables. In groups with more than two variables that were shown to have a statistically significant overall difference between groups, a Tukey's post hoc test was completed to determine the specific groups that differed.

The study received ethical approval from the University of Pittsburgh Institutional Review Board with the approval number PRO17080111.

\section{Results}

In 2013 , of 17,971 total injuries, 5,873 (32.7\%) were injury-related ER visits for patients aged 0-14 years. The average age of these patients was $7.4 \pm 4.2$ years, with $31.7 \%(1,862)$ children aged $0-4$ years, $32.4 \%(1,905)$ aged $5-9$ years, and $36.0 \%(2,114)$ aged $10-14$ years. The male to female ratio was $1.8: 1$, with $64.5 \%(3,790)$ male patients and $35.5 \%(2,083)$ female patients.

\section{Intentionality of Injuries}

Of the total injuries, $94.2 \%$ was unintentional, 3.9\% deliberate interpersonal injuries, and $1.9 \%$ self-inflicted. Table 1 includes intentionality of the injuries based on age-group, and Figure 1 displays intentionality based on the age-group and sex. Most injuries were unintentional, with $97.6 \%$ unintentional in preschool children, $96.6 \%$ unintentional in middle childhood, and $89.1 \%$ unintentional in adolescents. No self-inflicted injuries were reported among preschool children but $0.3 \%$ (6) in middle childhood and $4.9 \%$ (103) in early adolescents. In all, $2.4 \%$ (45) was of deliberate

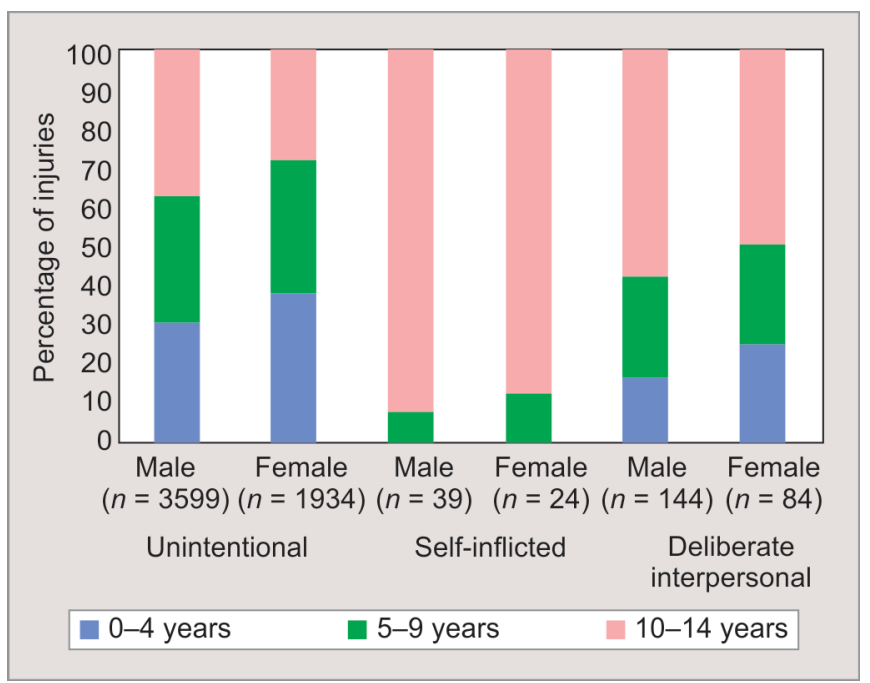

Fig. 1: Percentage of injuries in intentionality groups based on agegroup and sex of patients

interpersonal injuries in preschool children, 3.0\% (58) in middle childhood, and 6.0\% (127) in adolescents ( $p<0.0001)$.

The mean age of children injured by intent was $7.2 \pm 4.1$ years for unintentional injuries, $12.4 \pm 1.7$ years for self-inflicted injuries, and $9.3 \pm 4.1$ years for deliberate interpersonal injuries $(F=116.33, p<0.0001)$. Intentionality was significantly different by sex in early adolescence $(p<0.0001)$. Boys $(91.3 \%)$ were more 
Table 2: Mechanism of injury by age group for injured patients

\begin{tabular}{lccrc}
\hline Mechanism & $0-4$ Years $(n=1862), N(\%)$ & 5-9 Years $(n=1905), N(\%)$ & $10-14$ Years $(n=2114), N(\%)$ & Total $(n=5881), N(\%)$ \\
\hline Fall & $1,068(57.4)$ & $1,139(59.8)$ & $1,009(47.7)$ & $3216(54.7)$ \\
Trauma/blunt force & $164(8.8)$ & $233(12.2)$ & $318(15.0)$ & $715(12.2)$ \\
RTls & $99(5.3)$ & $177(9.3)$ & $254(12.0)$ & $530(9.0)$ \\
Bladed weapon & $47(2.5)$ & $76(4.0)$ & $120(5.7)$ & $243(4.1)$ \\
Foreign body & $99(5.5)$ & $55(3.0)$ & $46(2.2)$ & $200(3.5)$ \\
Gas/hot liquid & $107(5.8)$ & $33(1.7)$ & $41(1.9)$ & $181(3.1)$ \\
Poison/intoxication & $73(3.9)$ & $21(1.1)$ & $85(4.0)$ & $179(3.0)$ \\
Fire & $58(3.1)$ & $31(1.6)$ & $24(1.1)$ & $113(1.9)$ \\
Bites/stings & $26(1.4)$ & $30(1.6)$ & $48(2.3)$ & $104(1.8)$ \\
Other & $32(1.7)$ & $18(0.9)$ & $27(1.3)$ & $77(1.3)$ \\
Gunshot & $9(0.5)$ & $12(0.6)$ & $39(1.8)$ & $60(1.0)$ \\
Crushing & $12(0.6)$ & $11(0.6)$ & $27(1.3)$ & $50(0.9)$ \\
Sexual assault & $7(0.4)$ & $8(0.4)$ & $14(0.7)$ & $29(0.5)$ \\
Suffocation & $11(0.6)$ & $8(0.4)$ & $60(2.8)$ & $21(0.4)$ \\
Unknown & $50(2.7)$ & $53(2.8)$ & $163(2.8)$ \\
\hline Parson $\chi 2$ & & & \\
\hline
\end{tabular}

Pearson $\chi^{2}=356.6026 ; p<0.0001$

likely than girls $(84.2 \%)$ to have unintentional injuries; girls $(9.3 \%$ and $6.5 \%$, respectively) were more likely than boys $(5.4 \%$ and $2.9 \%$, respectively) to have self-inflicted injuries and deliberate interpersonal injuries, which was seen across all age-groups (Table 1).

\section{Mechanism of Injuries}

By age-group, older children had a higher percentage of RTIs, traumatic injuries, and violent injuries such as bladed weapons and gunshots compared to younger children $(p<0.0001)$. Younger children had a higher percentage of injuries due to falls, foreign bodies, hot liquids/gas, and fire compared to older children ( $p<$ 0.0001 ). As children in middle childhood (ages 6-11) transitioned to adolescence, they had fewer early childhood injuries due to foreign bodies, fire, or hot liquids/gas but more due to bladed weapons and RTIs ( $p<0.0001$ ). Table 2 shows the frequency and percentage of mechanisms of injuries by age group.

The most common unintentional injuries were $59.0 \%(3,176)$ falls, $11.7 \%$ (629) blunt force traumas, 9.9\% (530) RTIs, and 4.1\% (218) sharp object injuries. The most common deliberate interpersonal injuries consisted of $35.8 \%$ (81) blunt force traumas, $22.6 \%$ (51) gunshots, $12.8 \%$ (29) bites from another person, $12.8 \%$ (29) from sexual assault, and $9.7 \%$ (22) knife wounds. The most frequent selfinflicted injuries consisted of $59.6 \%$ (65) intoxications or poisonings, $29.4 \%$ (32) falls, and $4.6 \%$ (5) blunt force traumas.

Of the 532 RTIs, 257 (48.3\%) were pedestrians, 69 (13.0\%) were drivers, 162 (30.5\%) were passengers, and 44 (8.3\%) were unspecified RTIs. Of the 231 passengers and drivers, 22 (9.5\%) were known to use protection while 158 (68.4\%) did not. Of the 69 drivers, $46(66.7 \%)$ were riding a bicycle, 15 (21.7) were riding a motorcycle, $1(1.4 \%)$ was driving a truck, 4 (6.0\%) were riding an animal, and 1 (1.4\%) was driving a taxi.

Gang-related violence caused $5.1 \%$ (12) of the interpersonal injuries. Of these injuries, $83.3 \%$ (10) was in early adolescents, $8.3 \%$ (1) in children of middle childhood, and $8.3 \%$ (1) in preschool children. Fifty-one interpersonal injuries due to firearms. The aggressors were more likely someone with no relation to the victim (64.5\%), unspecified or unknown (19.6\%), or gang-related (13.7\%). When comparing firearm injuries to non-firearm intentional injuries, more known aggressors were gang related (13.7\% vs $2.8 \%$ ) or had no relation to the victim ( $64.5 \%$ vs $12.3 \% ; p<0.0001)$. Children injured by firearms were more likely to be older (10.2 \pm 3.9 years) than children injured by all other types of injuries $(7.3 \pm 4.1$ years; $p<0.0001)$.

\section{Place and Activity of Injuries}

Most injuries occurred at home (55.5\%) followed by those that happened on the streets (23.1\%). Male and female children aged 0-4 years had $79.4 \%$ and $82.2 \%$ of their injuries at home and $11.7 \%$ and $9.2 \%$ of their injuries on the streets, respectively ( $p=0.148)$. Male and female children aged $5-9$ years had $50.0 \%$ and $57.4 \%$ of their injuries at home and $28.1 \%$ and $21.8 \%$ on the streets, respectively $(p=0.007)$. Male children aged $10-14$ years had more injuries on the streets (33.8\%) than at home (31.5\%), while female children in the same age-group had more injuries at home (46.1\%) than from the streets $(26.3 \% ; p<0.0001$; Table 1$)$.

Children were most likely to be injured while doing recreational activities (70.8\%), traveling/walking (13.8\%), working (7.9\%), or studying (7.9\%). In older children, more injuries occurred during traveling/walking and working and fewer during recreation compared to younger children. Males were injured doing recreational activities compared to females in all age groups; $79.4 \%$, $75.9 \%$, and $63.0 \%$ of the total injuries were due to recreation in boys in early childhood, middle childhood, and early adolescence, and $78.2 \%, 70.1 \%$, and $56 \%$ of the total injuries were due to recreational activities in girls in early childhood, middle childhood, and early adolescence $(p<0.0005)$.

\section{Severity and Anatomical Locations of Injuries}

The majority of children (84\%) spent 3 or fewer days in the hospital. In all, 165 (2.8\%) children spent a substantial time in the hospital (more than 15 days) due to the severity of their injuries. Male children had longer hospital stay spending than female children, with $16.3 \%$ of males spending more than 3 days and $13.5 \%$ of females spending more than 3 days in the hospital $(p=0.005)$.

Severity score means by age-groups had no statistically significant difference, with an average severity score of $1.6 \pm 0.9$ 
for children of all ages ( $p=0.8833$ ). A significant difference was observed for severity score means between intentionality groups ( $F$ $=5.36, p=0.0048$ ) with a severity score of $1.6 \pm 0.9$ for unintentional injuries, $2.2 \pm 1.3$ for self-inflicted injuries, and $2.1 \pm 0.8$ for deliberate interpersonal injuries. The severity score mean was also higher for firearm injuries $(2.5 \pm 0.3)$ compared to non-firearm injuries (1.6 \pm $0.0 ; p=0.014)$.

Children with injuries due to firearms had a longer hospital stay than children with injuries due to other mechanisms. Most children (84.8\%) with injuries due to other mechanisms spent 3 or fewer days in the hospital while the majority of children with firearm injuries $(53.2 \%)$ spent 4 or more days in the hospital $(p<0.0001)$.

Head injuries (39.7\%), upper limb injuries (31.9\%), and lower limb injuries (15.5\%) were the most common locations for the sustained injuries. A significant difference was observed in anatomical location frequencies by age-group $(p<0.0005)$ with younger children having more head injuries and fewer limb injuries than older children. Separating by sex and age groups, male and female children aged $0-4$ years having $50.1 \%$ and $51.7 \%$ of injuries to the head, $25.5 \%$ and $21.1 \%$ to the upper limb, and $9.1 \%$ and $11.0 \%$ to the lower limb, respectively $(p=0.096)$. Male and female children aged $5-9$ years had $40.5 \%$ and $39.5 \%$ of injuries affecting the head, $38.3 \%$ and $33.1 \%$ the upper limb, and $12.1 \%$ and $14.1 \%$ the lower limb, respectively $(p<0.0005)$. Male and female children aged $10-14$ years had $30.4 \%$ and $27.4 \%$ of injuries in the head, $37.9 \%$ and $28.2 \%$ in the upper limb and $22.2 \%$ and $24.6 \%$ in the lower $\operatorname{limb}(p<0.0005)$.

The mortality rate was low with $14(0.2 \%)$ injuries resulting in death, with 6 (42.9\%) death in the youngest children, 3 (21.4\%) death of patients in middle childhood, and 5 (35.7\%) death in early adolescents. Unintentional injuries composed 13 (92.9\%) death, whereas 1 (7.1\%) death was caused by suicide. The only suicide completion was an early adolescent with a firearm. Of the unintentional deaths, 7 (53.8\%) were from RTIs, 3 (23.1\%) from falls, 1 (7.7\%) from a sharp object, 1 (7.7\%) from drowning, and 1 unspecified.

Of the children who died from their injuries, 11 (78.6\%) had injuries to the head, 2 (14.3\%) to the upper limb, and 1 (14.3\%) had injuries designated as other, which was different compared to those who did not die from their injuries $(p=0.039)$. Of the 2,334 injuries to the head, 1,399 (59.9\%) were of traumatic brain injury.

Injuries affecting the head $(1.8 \pm 0.9)$, trunk $(1.9 \pm 1.0)$, or other locations $(1.9 \pm 1.0)$ were the most severe; systemic injuries $(1.7 \pm$ $0.9)$ were moderately severe; and injuries affecting the upper limb $(1.3 \pm 0.7)$ or lower limb $(1.4 \pm 0.8)$ were less severe $(p<0.0001)$.

\section{Discussion}

Although there are many epidemiological studies regarding childhood injuries, most of these studies focused on high-income countries. This is the first study that specifically looks at childhood injuries in Honduras. Lack of comprehensive data on injuries in Honduras has led to a lack of targeted preventive strategies for pediatric injuries in the country. With over 5,000 recorded children aged under 15 years treated for injuries in the emergency department of UMSH in 2013, the need of understanding the mechanisms behind these injuries is clear.

Approximately one-third (32.7\%) of the total injuries occurred in children aged 0-14 years. This percentage is higher when compared to other similar studies in low- and middle-income countries (LMICs) such as a registry of injuries in Colombia, where $30.5 \%$ of the total injuries was found to be in people less than 18 years of age. ${ }^{14}$ In a registry in Bangladesh, children aged $0-14$ years composed $16.8 \%$ of the total injuries. ${ }^{15}$

More boys than girls were treated for their injuries, which is the trend around the world. ${ }^{16-19}$ Jalalvandi et al. suggested that this could be due to an increase in freedom for playing among boys in LMICs. ${ }^{19}$ Morrongiello and Dawber suggested that boys approach and touch hazards more than girls do and it takes more effort for mothers to redirect boys from these hazards. ${ }^{20}$ One study pointed out that boys cross streets unaccompanied more than girls do, a potential cause of increased RTIs in boys. ${ }^{21}$ Increased supervised child-care and increasing safe-play areas could be effective in reducing injuries in this population. ${ }^{22}$

Most injuries in children were unintentional. Injuries in Honduran children showed a similar trend in studies conducted in LMICs such as Nicaragua, ${ }^{16}$ Western Iran, ${ }^{19}$ central India, ${ }^{17}$ and Mozambique. ${ }^{18}$ The most common unintentional injuries were due to falls which is a trend reported in other studies in LMICs. ${ }^{16-19}$ Young children often fall from furniture and stairs. ${ }^{23}$ Simple and cost-effective fall prevention strategies in children are to use stair gates ${ }^{24}$ and also educating parents on these common injuries in children. ${ }^{25}$ Falls from playground equipment among schoolchildren are common and often severe, and not installing monkey bars ${ }^{26}$ or restricting the height of playground equipment ${ }^{27}$ could lower those injuries.

Another common unintentional injury was RTIs. A discrepancy is often observed between high-and low-income countries on the mechanisms for RTIs. In high-income countries, the majority of RTIs are suffered by vehicle occupants while the majority of RTIs in LMICs are suffered by vulnerable road users such as motorcyclists and pedestrians. ${ }^{28}$ Honduras does not have regular inspections of roads, policies separating road users from pedestrians or other vulnerable road users, and have national road safety strategy. ${ }^{29}$ Countries with similarities to Honduras has seen benefit in using cameras for detecting traffic violations, ${ }^{30}$ enforcing drinking and driving laws, ${ }^{31}$ separating physically vulnerable road users by creating motorcycle- and bicycle-exclusive lanes, ${ }^{32}$ increasing pedestrian crossing signs and clearly marking crosswalks, ${ }^{33}$ targeting motorcyclists or bicyclists not wearing helmets and designated vests, ${ }^{34}$ and targeting pedestrians crossing at prohibited places. ${ }^{34}$

In our study, the majority of children did not use protective devices such as a helmet or seatbelt at the time of the injury. Injuries to the head were the most frequent and severe, were likely to be a traumatic brain injury and had the most deaths of all anatomical locations of injury, highlighting the importance of prevention strategies such as the use of helmets. ${ }^{35}$ Other evidence-based and cost-effective interventions include the use and enforcement of seatbelts ${ }^{33}$ and the use of car restraints. ${ }^{24}$ The development of better vehicle and pedestrian guidelines would be beneficial for reducing some of the most severe and frequent injuries seen in children in Honduras.

Intentional injuries represented a much smaller yet significant portion of the total injury burden. The deliberate interpersonal injuries were more severe than the unintentional injuries, and they were primarily due to either blunt force trauma or gunshot wounds. Injuries by gunshots were more severe and caused a longer hospital stay than all other types of injuries and were more likely due to an unrelated person or gang member compared to all other mechanisms of injuries. The presence of gunshot wound injuries is concerning and highlights that children in this region are 
victims of social violence. Childhood exposure to violence causes psychological distress in children, ${ }^{36,37}$ and it can cause diagnosable psychiatric disorders in children and decreases the abilities children have to combat typical developmental challenges. ${ }^{37}$

Gang violence is prevalent and concerning in this region of Honduras, ${ }^{38}$ and in our study some children were victims of this type of violence. As of 2001, a total of 30,000 adolescents were estimated to be in gangs in this region. ${ }^{38}$ Known risk factors for recruitment into gangs include poverty, lack of opportunities, and separation from family members. ${ }^{39}$ Governmental attempts to control gang violence have largely been ineffective. ${ }^{39}$ One effort included territorializing different regions of the city into "barrios" (neighborhoods) in an attempt to make the rest of the city safer by controlling the area where gangs exist. Instead of making strides for gang member reduction and safety improvement, this strategy has been shown to strengthen the bonds and sense of belonging that gang members have to their gangs and increase transnational belonging to gangs. ${ }^{40}$ Possible prevention strategies include strengthening governability through the use and solidification of violence surveillance systems, ${ }^{41}$ increasing job training and support centers to keep children from joining gangs, and decreasing access to firearms. ${ }^{38}$ Honduras also lacks many recreation, sport, and artistic activities for youth which could keep youth from turning to gangs, ${ }^{39}$ and increasing these types of recreational environments would be one strategy to pursue.

Children who injured themselves were more likely to be older and primarily female. There is a failure to address mental health problems and provide mental health resources in adolescents, especially for survivors of violence, in LMICs. ${ }^{42,43}$ Specifically in Honduras, a lack of mental health resources for primary care and lack of differentiated care for children and adolescents ${ }^{44}$ was reported. Known warning signs of suicide include expressed suicide ideation or threats; substance abuse; the feeling of purposelessness or hopelessness; anxiety; withdrawal from friends, family, and society; recklessness; mood changes; and anger. ${ }^{45}$ Some important protective factors include access to mental hygiene, positive school connections, family stability, religious involvement, lack of weapons, and good relations with peers. ${ }^{45}$ Mood disorders, substance use, bullying, and other known risk factors related to suicide in adolescence should be routinely screened for by healthcare professionals. ${ }^{46}$ For those screened positive for mood disorder or a tendency to commit suicide, removal of firearms from the home and a variety of management options including use of antidepressants have been shown to be beneficial interventions. ${ }^{46}$ Knowing the warning signs, using widespread screening and evidence-based interventions, ${ }^{47}$ and promoting policies and education for mental health could be effective in reducing suicide attempts/completions in this population.

Although much was learned from the use of the InSS, it is not without limitations. With extensive medical records, it is possible to follow patients over time to determine the outcomes. Since the InSS only gives information on the one encounter the patient has in the ER, the development of a better medical record system is a necessary future goal for Honduras. Another limitation is that many injuries and deaths do not go through the hospital system due to the lack of resources such as transportation and finance, so the InSS is not able to include information on all injuries that occur in the region and just gives an overview of what is seen in the ER. Cases in this study are defined per patient, which makes it difficult to profile morbidity per injury. Patients with more than one injury are likely different than patients with only one injury, and our study is unable to explore or account for these differences. Finally, this study uses respondent's self-report about the history of the injury. Responses may be subject to social acceptability and recall bias although it would be nearly impossible to collect this information without the use of a questionnaire.

\section{Conclusion}

Childhood injuries are highly prevalent and a public concern throughout Honduras. This study profiles injuries of children who entered the main referral hospital of Tegucigalpa over an entire year and provides insight into the types of interventions that could be effective in preventing and managing the high burden of pediatric injuries in this region. Also, profiling injuries in LMICs have a wide array of challenges, and this study highlights the importance of collecting information about injuries for better resource allocation and calls for the development of a trauma registry in Honduras. Finally, we hope that other LMICs both regionally and worldwide can use this research to highlight the importance of childhood injuries in lower resource settings and develop targeted policies for injury prevention and management.

Further research is needed on childhood injuries in Honduras, such as trauma delivery and care, profiling community and domestic violence, expansion of care and injury profiling in areas with lack of access to care, and understanding the trends of injuries in this region over time. Once interventions have been implemented, studies will be needed to assess the effectiveness of these interventions.

\section{Clinical Significance}

This study provides the groundwork to understand the high burden of childhood injuries in Honduras and provides suggestions for injury prevention in this population. Targeted childhood injury prevention strategies in Honduras should be explored using the results of this study to most effectively make use of the public health resources available in Honduras.

\section{Ethical Standards Statement}

This study received ethical approval from the University of Pittsburgh Institutional Review Board with the approval number PRO17080111.

\section{References}

1. World Health Organization. Injuries and Violence - The Facts. Geneva 2014.

2. World Health Organization. World Report on Child Injury Prevention. Geneva 2008.

3. Haagsma JA, Graetz N, Bolliger I, et al. The global burden of injury: incidence, mortality, disability-adjusted life years and time trends from the global burden of disease study 2013. Inj Prev 2016;22(1):3-18. DOI: 10.1136/injuryprev-2015-041616.

4. Forward KE, Loubani E. Predictable and preventable: historical and current efforts to improve child injury prevention. Curr Pediatr Rev 2018;14(1):48-51. DOI: 10.2174/1573396313666171010111722.

5. Bonilla-Escobar FJ, Gutiérrez MI. Injuries are not accidents: towards a culture of prevention. Colomb Med 2014;45(3):132-135. DOI: 10.25100/ cm.v45i3.1462.

6. United Nations Office on Drugs and Crime. Global Study on Homicide. Vienna; 2013.

7. Pan-American Health Organization. Honduras - Health in the Americas. Washington, D.C 2007. 
8. Birken CS, Macarthur C. Socioeconomic status and injury risk in children. Paediatr Child Health 2004;9(5):323-325. DOI: 10.1093/ pch/9.5.323.

9. Bonilla-Escobar FJ, Rodriguez C, Puyana JC. Trauma care and surveillance: International "eCapacity" efforts and honduras experience. World J Surg 2017;41(9):2415-2416. DOI: 10.1007/s00268017-3969-8.

10. World Health Organization. Global Health Observatory (GHO) Data: Adult Mortality Rate, 2000-2016. Geneva 2020.

11. Rodriguez C, Bonilla-Escobar FJ, Restrepo-Lopera C, et al. A trauma registry experience from the main referral center of Honduras: A call for action. Injury 2019(4). DOI: 10.1016/j.injury.2019.03.022.

12. World Health Organization. Consolidated ARV guidelines, June 2013. Geneva 2019.

13. Krug EG, Mercy JA, Dahlberg LL, et al. The world report on violence and health. Lancet 2002;360(9339):1083-1088. DOI: 10.1016/S01406736(02)11133-0.

14. Ordoñez CA, Morales $M$, Rojas-Mirquez JC, et al. Trauma registry of the pan-american trauma society: one year of experience in two hospitals in southwest Colombia. Colomb Med (Cali) 2016;47(3):148-154. DOI: 10.25100/cm.v47i3.1763.

15. Rahman F, Ali Y, Andersson R, et al. Epidemiology of injury: results from injury registration at a district level hospital in Bangladeshimplications for prevention in low-income countries. Njury Control and Safety Promotion 2001;8(1):29-36. DOI: 10.1076/icsp.8.1.29.3367.

16. Martinez TML, Rocha CJ, Clavel-Arcas C, et al. Nonfatal unintentional injuries in children aged $<15$ years in Nicaragua. Int J Inj Contr Saf Promot 2010;17(1):3-11. DOI: 10.1080/17457300903525117.

17. Sharma S, Nayak A, Gupta R, et al. Pattern of pediatric trauma in rural background of central India. IJSS J Surg 2016;2(1):30-35.

18. de Sousa Petersburgo D, Keyes CE, Wright DW, et al. The epidemiology of childhood injury in Maputo, Mozambique. Int J Emerg Med 2010;3(3):157-163. DOI: 10.1007/s12245-010-0182-z.

19. Jalalvandi F, Arasteh $P$, Safari Faramani $R$, et al. Epidemiology of pediatric trauma and its patterns in Western Iran: a hospital based experience. Glob J Health Sci 2015;8(6):139-146. DOI: 10.5539/gjhs. v8n6p139.

20. Morrongiello BA, Dawber T. Toddlers' and mothers' behaviors in an injury-risk situation: implications for sex differences in childhood injuries. J Appl Dev Psychol 1998;19(4):625-639. DOI: 10.1016/S01933973(99)80059-8.

21. World Health Organization. Gender and Road Traffic Injuries. Geneva 2002.

22. Bartlett SN. The problem of children's injuries in low-income countries: a review. Health Policy Plan 2002;17(1):1-13. DOI: 10.1093/ heapol/17.1.1.

23. Pomerantz WJ, Gittelman MA, Hornung $R$, et al. Falls in children birth to 5 years: different mechanisms lead to different injuries. J Trauma Acute Care Surg 2012;73(4 Suppl 3):S254-S257. DOI: 10.1097/ TA.0b013e31826b017c.

24. Schnitzer PG. Prevention of unintentional childhood injuries. Am Fam Physician 2006;74(11):1864-1869.

25. Lallier M, Bouchard S, St-Vil D, et al. Falls from heights among children: a retrospective review. J Pediatr Surg 1999;34(7):1060-1063. DOI: 10.1016/S0022-3468(99)90564-X.

26. Mott A, Rolfe K, James R, et al. Safety of surfaces and equipment for children in playgrounds. Lancet 1997;349(9069):1874-1876. DOI: 10.1016/S0140-6736(96)10343-3.

27. Briss PA, Sacks JJ, Addiss DG, et al. Injuries from falls on playgrounds. Effects of day care center regulation and enforcement. Arch Pediatr Adolesc Med 1995;149(8):906-911. DOI: 10.1001/ archpedi.1995.02170210080014.

28. Ameratunga S, Hijar M, Norton R. Road-traffic injuries: confronting disparities to address a global-health problem.
Lancet 2006;367(9521):1533-1540. DOI: 10.1016/S0140-6736(06) 68654-6.

29. World Health Organization. Road Safety Status. Geneva 2013.

30. Martínez-Ruíz DM, Fandiño-Losada A, Ponce de Leon A, et al. Impact evaluation of camera enforcement for traffic violations in Cali, Colombia, 2008-2014. Accid Anal Prev 2019;125:267-274. DOI: 10.1016/j.aap.2019.02.002.

31. Bonilla-Escobar FJ, Herrera-Lopez ML, Ortega-Lenis D, et al. Driving under the influence of alcohol in Cali, Colombia: prevalence and consumption patterns, 2013. Int J Inj Contr Saf Promot 2016;23(2):179188.

32. Osorio-Cuellar GV, Pacichana-Quinayaz SG, Bonilla-Escobar FJ, et al. First motorcycle-exclusive lane (Motovia) in Colombia: perceptions of users in Cali, 2012-2013. Int J Inj Contr Saf Promot 2017;24(2):145-151. DOI: 10.1080/17457300.2015.1061563.

33. Forjuoh SN. Traffic-related injury prevention interventions for lowincome countries. Inj Control Saf Promot 2003;10(1-2):109-118. DOI: 10.1076/icsp.10.1.109.14115.

34. Gómez-Salazar GS, Bonilla-Escobar FJ, Morales-Quintero FJ, et al. Prevalence of traffic rule infractions in Cali, Colombia, at sites where injury crashes occurred. Int J Inj Contr Saf Promot 2017;24(2):158-164. DOI: 10.1080/17457300.2015.1080730.

35. Kiragu AW, Dunlop SJ, Mwarumba N, et al. Pediatric trauma care in low resource settings: challenges, opportunities, and solutions. Front Pediatr 2018;6:155. DOI: 10.3389/fped.2018.00155.

36. Shields N, Nadasen K, Pierce L. The effects of community violence on children in Cape Town, South Africa. Child Abuse Negl 2008;32(5):589-601. DOI: 10.1016/j.chiabu.2007.07.010.

37. Margolin G, Gordis EB. The effects of family and community violence on children. Annu Rev Psychol 2000;51(1):445-479. DOI: 10.1146/ annurev.psych.51.1.445.

38. Yacoub S, Arellano S, Padgett-Moncada D. Violence related injuries, deaths and disabilities in the capital of Honduras. Injury 2006;37(5):428-434. DOI: 10.1016/j.injury.2005.12.001.

39. Fogelbach JJ. Gangs, violence, and victims in El Salvador, Guatemala, and Honduras. San Diego Int'I LJ 2010;12:417.

40. Rivera LG. Discipline and punish? youth gangs' response to "zerotolerance" policies in Honduras. Bull Lat Am Res 2010;29(4):492-504. DOI: 10.1111/j.1470-9856.2010.00415.x.

41. Sanchez-Renteria G, Bonilla-Escobar FJ, Fandino-Losada A, et al. Citizen security observatories: tools for decision making and governability. Rev Peru Med Exp Salud Publica 2016;33(2):362-367. DOI: 10.17843/rpmesp.2016.332.2203.

42. Kieling $C$, Baker-Henningham $\mathrm{H}$, Belfer $\mathrm{M}$, et al. Child and adolescent mental health worldwide: evidence for action. Lancet 2011;378(9801):1515-1525. DOI: 10.1016/S0140-6736(11)60827-1.

43. Murray LK, Tol W, Jordans M, et al. Dissemination and implementation of evidence based, mental health interventions in post conflict, low resource settings. Intervention (Amstelveen) 2014;12(Suppl 1):94-112. DOI: 10.1097/WTF.0000000000000070.

44. World Health Organization. PHO, Ministry of Heatlh of Honduras,. Mental Health Systems in Honduras. Geneva 2008.

45. Dilillo D, Mauri S, Mantegazza C, et al. Suicide in pediatrics: epidemiology, risk factors, warning signs and the role of the pediatrician in detecting them. Ital J Pediatr 2015;41(1):49. DOI: 10.1186/s13052-015-0153-3.

46. Shain B, Committee On A. Suicide and suicide attempts in adolescents. Pediatrics 2016;138(1):e20161420. DOI: 10.1542/peds.20161420.

47. Bonilla-Escobar FJ, Fandiño-Losada A, Martínez-Buitrago DM, et al. A randomized controlled trial of a transdiagnostic cognitive-behavioral intervention for afro-descendants' survivors of systemic violence in Colombia. PLoS ONE 2018;13(12):e0208483. DOI: 10.1371/journal. pone. 0208483 . 